\title{
The E-rate Program and Libraries and Library Consortia, 2000-2004: Trends and Issues
}

The E-rate program has provided tremendous benefits to libraries, allowing many libraries and library systems to acquire technological equipment and services that would otherwise be too expensive, increasing the availability of public Internet access through libraries. This article analyzes the data related to the E-rate program and the discounts that it has provided to libraries and library systems between 2000 and 2004. By examining the E-rate data in a longitudinal manner, this article explores the trends in the application for and the provision of E-rate discounts to libraries and library consortia at national and state levels. The data suggest that, despite a number of controversies over the years, the program has provided a significant level of support for libraries and library consortia.

$\mathrm{T}$ he United States federal government established the E-rate program as part of the Telecommunications Act of $1996 .{ }^{1}$ The act placed great emphasis on universal service-the expansion of access to communication for previously underserved populations, particularly for those in rural and urban areas. ${ }^{2}$ A key part of these goals was the expansion of access to telecommunications for schools, libraries, and healthcare providers. Section 254(h) of the act, also known as the Snowe-RockefellerExon-Kerrey Amendment, created the education rate ("E-rate") program that allows for the application of discounts in telecommunications services, internal connections, and Internet services for schools, libraries, and healthcare providers. These discounts first became available in 1998, and the program makes as much as $\$ 2.25$ billion available every year for qualified organizations through the provision of discounts.

Recipients can have the discounts applied to their bills or receive reimbursements for specific services, depending on the communication needs of a recipient. The costs of the E-rate program are paid by funds collected from customers of telecommunications companies. The Universal Service Administrative Company (USAC), a nonprofit entity, oversees the distribution of

Paul T. Jaeger (jaeger@lis.fsu.edu) is Manager for Research Development, Charles R. McClure (cmcclure@lis.fsu.edu) is Francis Eppes Professor and Director, and John Carlo Bertot (bertot@lis.fsu.edu) is Professor and Associate Director of the Information Use Management and Policy Institute (www. ii.fsu.edu), College of Information, Florida State University, Tallahassee, Florida. the E-rate discounts. E-rate applications by libraries and library consortia are administered by USAC's Schools and Libraries Division (SLD) (www.sl.universalservice. org). The Federal Communications Commission (FCC) oversees USAC activities.

Libraries can qualify as applicants for E-rate discounts if they meet the definition of a library within the constraints of the Library Services and Technology Act and if they have a budget completely separate from a school. ${ }^{3}$ Libraries can apply individually or as part of consortia. Over its first six years, the program committed approximately $\$ 12$ billion in discounts, with the vast majority of E-rate discounts being awarded to schools. ${ }^{4}$ Since the program began awarding discounts, libraries and library consortia have consistently received 3 to 4 percent of total E-rate discounts each year. ${ }^{5}$ This emphasis on schools as the highest funding priority has also been reflected in analyses of the social effects of the program, which have focused heavily on E-rate in schools. ${ }^{6}$

The program allows libraries to apply for discounts between 20 and 90 percent for services related to the provision of communication, including Internet access, internal connections, and telecommunications services. The level of the discount varies according to economic need of the community served by the applicant and if the applicant serves a rural or urban area. As an indicator of need, USAC assesses libraries' applications in terms of the percentage of students eligible to receive free or reduced-price lunches from the National School Lunch Program in the library service area (www. sl.universalservice.org/Reference/eligible.asap).

Although there are other external sources of funding for communications and technology available to libraries, the E-rate program has become very important to libraries in the United States. ${ }^{7}$ In June 2002, for example, 43.4 percent of public libraries were receiving E-rate discounts. ${ }^{8}$ Many libraries that could qualify for E-rate discounts, however, do not apply because they are unaware of their eligibility, they feel they lack sufficient staff to implement new technologies, or they do not understand the complexities of the application process. $^{9}$

The E-rate program has provided a significant level of technology support to libraries, allowing many libraries and library systems to acquire technological equipment and services that would otherwise be too expensive. In libraries and library consortia over the course of the E-rate program, internal connections have ranged from 13 percent to 21 percent of total discounts, Internet access has ranged from 12 percent to 29 percent of total discounts, and telecommunications services have ranged from 53 percent to 67 percent of total discounts. ${ }^{10}$ Though E-rate has clearly provided significant benefits to libraries and library consortia during its existence, 
several recent issues threaten to alter the role of the program and the benefits that it provides.

\section{Selected E-rate Program Issues}

The E-rate program has not been immune to controversies or external pressures. Various elements of the program have been questioned by both supporters, who feel that the program is not expansive enough, and detractors, who feel that the program is too broad in scope or too heavily funded. ${ }^{11}$ Considerable problems with the uses of funds in certain cases have also become an issue. Assessments by the Government Accountability Office (until recently known as the General Accounting Office) have noted problems with the E-rate program due to incorrect awards, failure to distribute awards, and lack of proper financial oversight. ${ }^{12}$ Some recipients of the discounts, such as certain public school systems, have purchased more technology and services than they can afford to maintain, have purchased unnecessary technology and services, or have never used what they have acquired. ${ }^{13}$

The E-rate program has also become embroiled in the contentious issue of the filtering of Internet access on computers in public libraries due to the enactment of the Children's Internet Protection Act (CIPA). ${ }^{14}$ If a library receives certain E-rate discounts, the library must comply with CIPA, which requires the use of filters to block access to certain Internet content. As of July 2004, a public library or public school library must install technology protection measures (usually referred to as filters or filtering software) if it receives federal E-rate discounts for Internet access costs or internal connections costs. If a library decides that it does not wish to install filters to meet CIPA requirements, the library must forgo receipt of these types of E-rate discounts. This requirement creates many issues that libraries must face when considering whether to apply for E-rate discounts and has significant implications for library service and technology planning in these libraries. ${ }^{15}$

From August through mid-December of 2004, a temporary moratorium was imposed on the distribution of E-rate discounts and other USAC programs. The FCC decided to impose tighter accounting and spending rules on USAC, requiring E-rate awards to be based on funds currently available rather than its previous practices of awarding funds that SLD estimated it would have. As a result of the change in accounting practices, the distribution of more than a billion dollars in awards for 2004 to schools and libraries was temporarily stalled. Because of the temporary moratorium, as many as 80 percent of 2004 applicants faced delays in receiving decisions about the discounts for which they applied. ${ }^{16}$ Though now resolved, this situation had the potential to cause many funding problems and possible disruptions in Internet and telecommunications services in many libraries, particularly libraries with smaller budgets and those in economically disadvantaged communities.

\section{Method}

USAC graciously provided the researchers the most recent data tables for the funding years of 2000 to 2004 for the E-rate program. The data specifically covers the funding to libraries and library consortia through SLD. The dataset is current as of August 2004. Due to continual changes in the status of many applications on an ongoing basis, as many funding decisions are made about pending applications and as some funded programs are discontinued, the numbers in this dataset can only provide a point in time snapshot of the data.

The researchers analyzed these data tables to identify key trends and information from the large amount of data related to E-rate funding of libraries. Some of the research questions that guided the analysis of data included:

- What is the number of all applications between 2000 and 2004 ?

- What is the amount of all awards between 2000 and 2004 ?

- What are the trends over 2000-2004 in the awarding of discounts?

- Which individual states (inclusive of United States territories) have been more or less successful in obtaining E-rate awards?

The answers to these questions build upon findings from previous work by the researchers that analyzed E-rate funding data. ${ }^{17}$

Approvals of E-rate applications are not fixed in the particular year that an application is submitted. For every year analyzed in this article, there are many applications that are still pending. Some discount recipients only use a percentage of the award amount, due primarily to the fact that libraries have to estimate future need when applying because E-rate applications must be made so far in advance of the time that funds will be needed. Further, the funding for certain programs has been discontinued after an initial decision to fund the program. All of these factors affect the data that is analyzed in this article.

Finally, there are some inconsistencies in the dataset across different sources of data provided. USAC handles an enormous amount of complex data for the program, with the status of many applications changing on a daily basis. For this article, figures were crosschecked within the dataset, and, if inconsistencies were found, the numbers were recalculated to try to determine the most accu- 
rate figures possible. If any inconsistencies for a certain type of data could not be resolved, that particular type of data was not used in this article.

It is important to emphasize that the data at hand relates exclusively to libraries and library consortia. This point is particularly important because some libraries receive the benefits of E-rate as a part of a consortium that includes schools and libraries. A library, for example, may receive an E-rate discount as part of an application from a consortium that includes a system of public schools and libraries. Alternately, a library may receive E-rate discounts in tandem with a school. Cases such as these are not covered by the data herein because E-rate data is not kept in a manner that allows for the extraction of individual benefits to libraries that apply with schools. As such, some libraries benefiting from E-rate are not part of the dataset at hand.

\section{Analysis of E-rate Data from 2000-2004}

The data related to E-rate discounts to libraries and library consortia are complex and reveal many different types of information about the E-rate program's effects on libraries in the United States. As such, this discussion describes topics that seem to be the most significant in terms of the amounts of E-rate discounts going to libraries and library consortia, focusing on award amounts, number of denials, and the areas that are being most affected by the program across the nation. In all of these cases, the discounts awarded for technology have been a significant benefit for libraries and library consortia, allowing them greatly to increase access to the Internet and other services for staff and patrons.

For the time period in question, as table 1 demonstrates, the annual total amount of E-rate requests made by libraries and library consortia are quite similar, with the year 2001 being an exception. For the years excluding 2001, the number of applications ranged from 12,397 to 15,537 , for requested amounts from $\$ 86,747,316.28$ to $\$ 107,138,124.52$. There are no obvious reasons in the data for the spike in the number applications $(23,714)$ and the amount requested $(\$ 152,473,787.27)$ in 2001. Over the period from 2000 to 2004 , the average annual number of requests has been 15,955 and the average annual amount requested has been $\$ 108,152,443.08$.

As the annual amount requested by libraries and library consortia from the E-rate program has been typically similar, the annual amount of discounts committed to libraries and library consortia has been similar. Table 2 shows that, between 2000 and 2003, the range of discounts awarded has been from $\$ 57,853,129$ to $\$ 66,054,175$.
Table 1. Number of Requests and Funds Requested 2000-2004

\begin{tabular}{lrr} 
Year & No. of Requests & Amount Requested \\
\hline 2000 & 14,945 & $\$ 106,317,692.06$ \\
2001 & 23,714 & $\$ 152,473,787.27$ \\
2002 & 15,537 & $\$ 107,138,124.52$ \\
2003 & 13,183 & $\$ 88,085,295.29$ \\
2004 & 12,397 & $\$ 86,747,316.28$ \\
TOTAL & 79,776 & $\$ 540,762,215.42$ \\
\hline
\end{tabular}

Note: Current as of August 2004.

Table 2. Funds Committed to Libraries 2000-2003

\begin{tabular}{lr}
\hline Year & Amount Committed \\
\hline 2000 & $\$ 66,054,175.00$ \\
2001 & $\$ 57,853,129.00$ \\
2002 & $\$ 63,079,407.00$ \\
2003 & $\$ 63,329,428.00$ \\
TOTAL & $\$ 250,316,139.00$ \\
\hline
\end{tabular}

Note: Current as of August 2004, when funding decisions for 2004 applications had not yet been made. Discount awards are rounded to the nearest dollar.

Over these four years, the average amount of discounts awarded has been $\$ 62,579,034.75$.

A large number of applications to E-rate have been denied between the years 2000 and 2003. These denials can occur because a library or library consortia requests discounts for which they are not eligible or that are beyond the parameters of E-rate, even though determining eligibility of a particular service may be difficult for some libraries. If an application includes a certain percentage of requests that the applicant is not eligible for, the whole application can be denied. Applications may also be denied due to overall demand for E-rate discounts. In 2004, applications to the entire E-rate program were for $\$ 4.7$ billion, while the fund only had $\$ 2.25$ billion to award. ${ }^{18}$

Between 2000 and 2003, a total of $\$ 115,612,444.14$ in E-rate requests by libraries and library consortia have been denied (see table 3). The average for denials over this four-year period is $\$ 28,903,111.04$. The highest amount of discounts denied is for the year 2001, which had an inordinately high amount of discounts requested. The 
Table 3. Amounts of Requests Denied as of August 2004

\begin{tabular}{lr} 
Year & Amount Denied \\
\hline 2000 & $\$ 29,735,504.60$ \\
2001 & $\$ 50,803,327.05$ \\
2002 & $\$ 28,660,088.49$ \\
2003 & $\$ 6,413,524.00$ \\
TOTAL & $\$ 115,612,444.14$ \\
\hline
\end{tabular}

Note: Current as of August 2004, when funding decisions for 2004 applications had not yet been made.

Table 4. Amounts of E-rate Applications Pending as of August 2004

Year Amount Pending

2000 $\$ 9,707,637.09$

2001

$\$ 40,698,549.98$

2002

$\$ 11,549,575.52$

2003

$\$ 14,114,014.60$

TOTAL

$\$ 76,069,777.19$

Note: Current as of August 2004, when funding decisions for 2004 applications had not yet been made.

total amount of discounts denied between 2000 and 2003 is approximately 46 percent of the amount of discounts awarded in the same timeframe.

When SLD assesses E-rate applications, they may be funded, denied, or kept as pending for further review. For each of the years at issue in this discussion, a considerable number of applications are still officially pending (see table 4). It seems surprising to find that $\$ 9,707,637.09$ in applications from 2000 are still pending, as the passage of four years for a decision about E-rate discounts would likely have implications for a library's financial and technological decisions. The high dollar amount of pending applications from 2001 parallels the unusually high level of applications in 2001. For 2000 to 2003, the average amount pending is $\$ 19,017,444.29$ per year, while the total amount pending from the four years is $\$ 76,069,777.19$.

When SLD funds an application, it is often not funded for the full amount requested. It is not uncommon for applicants to include items in an application that are beyond the scope of E-rate or to apply for discounts for which they do not qualify in an application that is otherwise appropriate. Further, in some cases, programs that were initially funded have been discontinued either by USAC or by the grant recipient. As a result, the amount of discounts awarded combined with the amount of discounts denied does not equal the total amount of discounts applied for.

When E-rate awards to libraries and library consortia are viewed in relation to the amounts awarded to libraries and library consortia in individual states, a distinct pattern emerges. As table 5 shows, libraries and library consortia in certain states are quite successful in receiving E-rate discounts. From the years 2000 to 2003, the top five states receiving E-rate discounts are almost the same every year. New York was the top recipient state for discounts to libraries and library consortia each of the four years. California, Georgia, and Texas were also in the top five recipients each of the four years.

These states are all among the states with larger numbers of libraries, meaning they have a larger number of libraries and library consortia to apply for discounts. The states receiving the most E-rate discounts may also have better statewide organization to encourage libraries to apply. Table 6 shows the top five states for 2000 to 2003 by the amount of funds requested. Most of the top five recipients of each year (table 5) are among the top five requesters in each year (table 6). In fact, New York was both the top requester and the top recipient in 2000 to 2003. The primary exception to the correlation is Puerto Rico, which requested high amounts of discounts in 2001, 2002, and 2003 with limited success. An average of 3.5 states appear in both the top five requesters and the top recipients by amount in each year between 2000 and 2003.

Table 7 contains the number of E-rate applications from libraries and library consortia from each state by year. For most states, the number of applications tends to fluctuate yearly. In some cases, the numbers of applications are fairly similar from year to year, such as North Dakota, which has submitted between twenty-one and thirty applications each year. Other states have significant variation in the number of applications each year. California has had the most significant variations over the five-year period, with a low of 334 applications in 2004 and a high of 2,187 applications in 2001. A significant spike in the number of application by some statesCalifornia, Connecticut, Florida, Illinois, Michigan, New York, and Pennsylvania-account for many of the abnormal numbers of E-rate applications in 2001. In the case of each of these states, the number of applications dropped considerably in 2002.

As tables 5 and 7 demonstrate, the dollar amount of discounts received is not directly tied to the population of the state (based on the numbers of 2000 national census). Between 2000 and 2003, the top five states in each year have notable variations in population size, resulting in very different per capita amounts for the E-rate awards. The range across the four years in these top five states spans an average of less than $\$ 0.10$ per state resident in one year (California in 2000) to more than $\$ 1.20$ per 
Table 5. Top Five Funds Committed by State with Amounts per Capita by 2000 Census from 2000-2003

\begin{tabular}{lrr}
\hline State & Funds Committed & Amount per Capita \\
\hline 2000 & & \\
\hline 1. New York & $\$ 15,459,189$ & $\$ 0.815$ \\
2. Texas & $\$ 5,626,750$ & $\$ 0.270$ \\
3. Georgia & $\$ 5,293,855$ & $\$ 0.647$ \\
4. California & $\$ 3,080,907$ & $\$ 0.091$ \\
5. Florida & $\$ 3,020,582$ & $\$ 0.189$ \\
2001 & & \\
\hline 1. New York & $\$ 14,620,638$ & $\$ 0.770$ \\
2. Georgia & $\$ 5,421,769$ & $\$ 0.662$ \\
3. Massachusetts & $\$ 4,140,859$ & $\$ 0.652$ \\
4. California & $\$ 3,309,200$ & $\$ 0.098$ \\
5. Texas & $\$ 3,001,074$ & $\$ 0.144$ \\
2002 & & \\
\hline
\end{tabular}

\begin{tabular}{lrr}
\hline 1. New York & $\$ 11,157,571$ & $\$ 0.588$ \\
2. Massachusetts & $\$ 7,764,419$ & $\$ 1.223$ \\
3. Georgia & $\$ 5,548,504$ & $\$ 0.678$ \\
4. Texas & $\$ 4,211,681$ & $\$ 0.202$ \\
5. California & $\$ 3,792,070$ & $\$ 0.112$ \\
2003 & & \\
\hline 1. New York & $\$ 11,598,217$ & $\$ 0.611$ \\
2. Georgia & $\$ 5,398,090$ & $\$ 0.659$ \\
3. California & $\$ 4,761,539$ & $\$ 0.141$ \\
4. Texas & $\$ 3,660,542$ & $\$ 0.176$ \\
5. Massachusetts & $\$ 2,915,557$ & $\$ 0.459$ \\
\hline
\end{tabular}

Note: Current as of August 2004, when funding decisions for 2004 applications had not yet been made.

state resident in one year (Massachusetts in 2002). Table 7 shows the top five recipients of E-rate discounts for libraries and library consortia by per capita amount of discount in terms of 2000 census data.

Table 8 shows that the states that have had the most success annually on a per capita basis are less consistent on an annual basis than the top states in terms of amounts of discounts (table 5). Many of the states in the top five by amount of a particular year, however, also appear in the top five by per capita discounts. In fact, an average of three states appear in both the top five by amount and by per capita each year. New York appears in the top five by per capita discounts for every year between 2000 and 2003. As table 9 evidences, there are considerable variations in E-rate discounts per capita across all states. The level of support for libraries making E-rate applications within each state (such as by consortia or state library agency) may help to explain variations in per capita discounts.

As with the number of applications by state (table 7), table 9 shows that amounts of E-rate discounts by state per capita tend to similarly fluctuate from year to year. A few states, such as Arkansas and Oklahoma, have managed to increase the per capita amount of awards each year. Some states have received remarkably similar awards each year per capita, such as Georgia, which has received between $\$ 0.647$ (in 2000) and $\$ 0.678$ (in 2002) per capita each year. Other states have had wide variations in the amount of awards per capita, such as Puerto Rico, which received a low of $\$ 0.000$ (in 2001 and 2003) and a high of $\$ 1.170$ (in 2000).

\section{Discussion of Data}

The data on E-rate support of libraries and library consortia raise a number of issues. A most basic issue is the fact that we do not know exactly how much E-rate support actually goes to libraries. Without information about the amount of support received by libraries participating in school and library consortia, the level of support of libraries remains underreported. Thus, the amount of total library awards is more than can be reported in this article.

The data do raise a number of questions about the reasons that underlie decisions by SLD to fund or deny a request. As the breakdown of applications by state shows, requesting a large amount of discounts often leads to receiving a large amount of discounts. However, applying for a large amount of discounts is no guarantee of success. To provide guidance to those making applications, it would very helpful to have a better understanding of why certain libraries, such as New York libraries and library consortia, are so successful at receiving E-rate discounts. Successful E-rate applicants may have much to teach less successful ones.

Similarly, it would be valuable to know the reasons for denials of applications. The reasons could include ineligible requests, incomplete applications, lack of funds, low-priority location, and many other potential reasons. Also, it would be useful to know what factors in an application cause it to be funded at an amount below what was requested. There is no way of knowing, however, based 
on the available data, which of these potential reasons for denials have the largest impact on the evaluation of E-rate applications.

The reasons for approvals and denials may depend on a host of possible factors. Some states, notably through the state library or through regional library consortia, encourage libraries to apply and provide direct assistance to the libraries when completing the applications. The American Library Association (ALA) has an E-rate Task Force that has regular conference calls with FCC and SLD, and many state E-rate coordinators participate in these calls. Local factors at individual libraries, such as knowledge about how to complete the applications or how the library operates within the municipal government, vary considerably.

Another important aspect of the awards process is the continuing status of many applications as pending. The causes for applications remaining pending may be related to problems with an application, issues that must be addressed by an applicant, or issues of implementation. Regardless of the reasons, it seems likely that an applicant who requested E-rate discounts in 2000 and has yet to receive a determination needs to inquire why the award is pending to move it to either accepted or denied.

Aside from issues related to the application process, this data brings into view other significant considerations of the E-rate program. The most obvious is that the information about award amounts and which states receive the greatest amounts of discounts reveals nothing about the actual impact of the program on libraries or library patrons. Much has been made of the amount of discounts allocated by the program and the number of new technologies that have been acquired and installed. Research, however, has not examined the social effects of the items acquired with E-rate discounts to see if the materials have resulted in increased library usage, Internet usage, computer literacy, higher student test scores, or other measures of change that could be linked to the availability of the technology. In light of the recent investigations of various misuses of E-rate awards, the need for a clearer picture of the actual effects of the E-rate program is all the more pressing. ${ }^{19}$ The available data are silent on issues of the degree to which program goals have been accomplished, effects, outcomes, benefits, and uses.

In the near future, the relationship of E-rate to libraries and library consortia may change significantly. In 2002, 43.4 percent of public libraries were receiving E-rate discounts; of those, 18.9 percent indicated that they would not continue to apply for E-rate discounts should CIPA be upheld. ${ }^{20}$ Whether libraries and library consortia will reduce their applications to the E-rate program over the course of many years to avoid the requirements of CIPA remains an important but unanswered question that has implications for both libraries and the E-rate program.
Table 6. Top Five States by Total Amount of Funds Requested from 2000-2004

State

Funds Requested

2000

1. New York

$\$ 21,778,875.55$

2. Pennsylvania

$\$ 7,339,033.91$

3. Texas

$\$ 7,186,418.87$

4. Georgia

$\$ 6,492,703.64$

5. California

$\$ 5,814,419.14$

2001

1. New York

$\$ 29,960,184.93$

2. Puerto Rico

$\$ 13,073,577.47$

3. California

$\$ 12,129,263.67$

4. Florida

$\$ 8,598,386.84$

5. Michigan

$\$ 7,805,425.44$

2002

1. New York

$\$ 16,904,262.75$

2. Massachusetts

$\$ 13,776,711.40$

3. Puerto Rico

$\$ 9,052,298.20$

4. California

$\$ 7,014,226.56$

5. Georgia

$\$ 6,284,213.85$

2003

1. New York

$\$ 12,888,033.68$

2. California

$\$ 6,369,427.76$

3. Puerto Rico

$\$ 6,190,270.21$

4. Texas

$\$ 6,146,110.03$

5. Georgia

$\$ 5,558,671.98$

2004

1. New York

$\$ 24,380,331.03$

2. Texas

$\$ 4,880,244.43$

3. Georgia

$\$ 4,748,272.27$

4. Illinois

$\$ 4,116,705.24$

5. California

$\$ 3,971,579.30$

Note: Current as of August 2004, when funding decisions for 2004 applications had not yet been made. 
Table 7: Total Number of Applications from 2000-2004 by State

\begin{tabular}{|c|c|c|c|c|c|c|c|c|c|c|c|}
\hline State & 2000 & 2001 & 2002 & 2003 & 2004 & State & 2000 & 2001 & 2002 & 2003 & 2004 \\
\hline Alabama & 246 & 347 & 317 & 274 & 304 & Nebraska & 288 & 326 & 279 & 324 & 276 \\
\hline Alaska & 90 & 131 & 104 & 84 & 74 & Nevada & 67 & 152 & 89 & 86 & 71 \\
\hline Arizona & 244 & 491 & 283 & 224 & 244 & New Hampshire & 93 & 100 & 47 & 43 & 21 \\
\hline Arkansas & 125 & 141 & 119 & 133 & 138 & New Jersey & 294 & 918 & 326 & 306 & 245 \\
\hline California & 451 & 2187 & 642 & 446 & 334 & New Mexico & 71 & 172 & 135 & 89 & 89 \\
\hline Colorado & 322 & 303 & 211 & 233 & 195 & New York & 1442 & 2571 & 1561 & 1077 & 996 \\
\hline Connecticut & 114 & 605 & 164 & 123 & 92 & North Carolina & 310 & 428 & 406 & 383 & 359 \\
\hline Delaware & 33 & 53 & 34 & 30 & 30 & North Dakota & 29 & 24 & 30 & 21 & 23 \\
\hline District of Columbia & 5 & N/A & 1 & 3 & 1 & Northern Mariana & & & & & \\
\hline Florida & 470 & 1548 & 574 & 416 & 363 & Islands & N/A & 4 & N/A & 10 & N/A \\
\hline Georgia & 173 & 324 & 240 & 194 & 243 & Ohio & 193 & 323 & 222 & 176 & 391 \\
\hline Guam & 9 & 6 & N/A & N/A & N/A & Oklahoma & 509 & 478 & 463 & 421 & 448 \\
\hline Hawaii & 110 & 103 & 102 & 159 & 165 & Oregon & 265 & 308 & 141 & 123 & 119 \\
\hline Idaho & 89 & 120 & 106 & 146 & 96 & Pennsylvania & 793 & 1387 & 933 & 799 & 775 \\
\hline Illinois & 939 & 1252 & 992 & 829 & 690 & Puerto Rico & 291 & 589 & 557 & 506 & 126 \\
\hline Indiana & 469 & 460 & 377 & 329 & 353 & Rhode Island & 39 & 69 & 38 & 29 & 29 \\
\hline lowa & 598 & 509 & 395 & 394 & 319 & South Carolina & 69 & 98 & 67 & 174 & 119 \\
\hline Kansas & 329 & 371 & 425 & 447 & 424 & South Dakota & 38 & 35 & 25 & 45 & 39 \\
\hline Kentucky & 388 & 374 & 311 & 278 & 236 & Tennessee & 564 & 557 & 481 & 421 & 379 \\
\hline Louisiana & 197 & 216 & 197 & 181 & 251 & Texas & 773 & 913 & 624 & 716 & 582 \\
\hline Maine & 80 & 153 & 162 & 140 & 124 & Utah & 63 & 53 & 26 & 49 & 28 \\
\hline Maryland & 131 & 258 & 148 & 106 & 121 & Vermont & 134 & 147 & 111 & 117 & 62 \\
\hline Massachusetts & 120 & 662 & 161 & 77 & 64 & Virgin Islands & 4 & N/A & N/A & N/A & N/A \\
\hline Michigan & 557 & 1028 & 552 & 528 & 481 & Virginia & 281 & 350 & 279 & 325 & 282 \\
\hline Minnesota & 150 & 239 & 191 & 153 & 162 & Washington & 514 & 456 & 397 & 390 & 371 \\
\hline Mississippi & 354 & 328 & 536 & 404 & 332 & West Virginia & 264 & 279 & 267 & 236 & 212 \\
\hline Missouri & 132 & 168 & 154 & 127 & 137 & Wisconsin & 299 & 278 & 238 & 206 & 152 \\
\hline Montana & 226 & 213 & 206 & 199 & 159 & Wyoming & 90 & 88 & 67 & 54 & 41 \\
\hline
\end{tabular}

Note: Current as of August 2004. "N/A" indicates no applications were received from a state that year.

\section{Need for Additional Research}

Additional research will be required to ensure that the technological benefits from the E-rate program continue into the future and are used effectively. To this point, the information available on the E-rate program is related to the number and amount of awards. Given that the program is into its seventh year of granting awards, the program's actual effects clearly merit detailed investigations that explore issues related to how exactly the discounts are being used and if the technologies that result actually are making an impact on availability and use of the Internet. Libraries and library consortia have received considerable amounts of discounts from the program, yet 
Table 8. Top Five States for Funds Committed Per Capita by 2000 Census from 2000-2003

\section{State} Funds per Capita

2000

1. Puerto Rico

$\$ 1.170$

2. New York

$\$ 0.815$

3. Virgin Islands

$\$ 0.728$

4. Georgia

$\$ 0.647$

5. Massachusetts

$\$ 0.438$

\section{1}

1. New York

$\$ 0.770$

2. Georgia

3. Massachusetts

$\$ 0.652$

4. Minnesota

5. Louisiana

$\$ 0.327$

2002

1. Massachusetts

2. Georgia

$\$ 0.678$

3. New York

4. Mississippi

$\$ 0.445$

5. Louisiana

$\$ 0.344$

2003

1. Georgia

$\$ 0.659$

2. New York

$\$ 0.611$

3. Mississippi

$\$ 0.498$

4. Massachusetts

$\$ 0.459$

5. Oklahoma

$\$ 0.364$

Note: Current as of August 2004, when funding decisions for 2004 applications had not yet been made.

no detailed information is available regarding the meaning of the E-rate program in libraries that have received discounts.

To understand if the E-rate program is achieving its goals through libraries and library consortia, research must begin to address the issues related to the implementation of E-rate discounts in libraries. Potential areas of future research for the library community could include:
- Program Goals. More research needs to examine the extent to which the E-rate program is accomplishing its mission. To what degree have the E-rate program goals been accomplished, and what changes might need to be made in the program to better accomplish program goals?

- Effects. Further research needs to address the actual effects of E-rate discounts in libraries and library consortia. What services are being acquired using the discounts? Are these enhancements to existing services, or would the services otherwise be unavailable? Are discounts being used to meet the needs of patrons, staff, or both? What are the effects in communities around libraries that receive E-rate discounts? What are the effects of E-rate discounts on the availability and use of technology in libraries?

- Uses. The recent revelations about misuses of some E-rate discounts in schools indicate the need for research investigating how well recipients use E-rate awards. Are the awards being used in line with the application? Are the services acquired with the discounts being used properly or at all? Are applicants receiving more than they need?

- Applications process. Decisions on many applications are delayed because of problems during the application process, which can be very complex. ALA and other library agencies and organizations have made a number of formal suggestions intended to simplify the application process to the FCC. Are there ways, drawing upon the experiences of those who have made applications and upon the suggestions from library agencies and organizations, that the process could be improved to facilitate the submission and review of applications?

- Timeframe for decisions and distributions. The large number of applications that remain pending for a year or more is cause for concern, particularly for applicants still awaiting decisions. Are there ways to modify the application and review processes to reduce the number of applications that are classified as pending?

- Links to other data. The E-rate data related to libraries and library consortia could be linked to other types of funding data on libraries and library consortia-related to technology. Doing so might help provide a better understanding of the role of E-rate within the greater picture of libraries and funding. Do libraries receiving E-rate discounts generally receive fewer dollars for technology from other sources? Or do libraries receiving E-rate discounts also receive significant funding for technology from other sources? What other sources of funds (national, state, local, or private) do libraries and library consortia seek for technology along with E-rate discounts?

- CIPA Effects. CIPA's filtering requirements are now being imposed on many libraries that receive E-rate 
Table 9. Funds Committed in Dollars Per Capita by 2000 Census from 2000-2003 by State

\begin{tabular}{|c|c|c|c|c|c|c|c|c|c|}
\hline State & 2000 & 2001 & 2002 & 2003 & State & 2000 & 2001 & 2002 & 2003 \\
\hline Alabama & $\$ 0.144$ & $\$ 0.153$ & $\$ 0.171$ & $\$ 0.170$ & Nebraska & $\$ 0.118$ & $\$ 0.123$ & $\$ 0.129$ & $\$ 0.171$ \\
\hline Alaska & $\$ 0.174$ & $\$ 0.230$ & $\$ 0.207$ & $\$ 0.226$ & Nevada & $\$ 0.035$ & $\$ 0.048$ & $\$ 0.047$ & $\$ 0.140$ \\
\hline Arizona & $\$ 0.079$ & $\$ 0.087$ & $\$ 0.127$ & $\$ 0.158$ & New Hampshire & $\$ 0.051$ & $\$ 0.038$ & $\$ 0.018$ & $\$ 0.023$ \\
\hline Arkansas & $\$ 0.022$ & $\$ 0.029$ & $\$ 0.033$ & $\$ 0.037$ & New Jersey & $\$ 0.121$ & $\$ 0.124$ & $\$ 0.196$ & $\$ 0.131$ \\
\hline California & $\$ 0.091$ & $\$ 0.098$ & $\$ 0.112$ & $\$ 0.141$ & New Mexico & $\$ 0.230$ & $\$ 0.099$ & $\$ 0.098$ & $\$ 0.291$ \\
\hline Colorado & $\$ 0.182$ & $\$ 0.111$ & $\$ 0.101$ & $\$ 0.170$ & New York & $\$ 0.815$ & $\$ 0.770$ & $\$ 0.588$ & $\$ 0.611$ \\
\hline Connecticut & $\$ 0.088$ & $\$ 0.121$ & $\$ 0.147$ & $\$ 0.125$ & North Carolina & $\$ 0.223$ & $\$ 0.167$ & $\$ 0.163$ & $\$ 0.171$ \\
\hline Delaware & $\$ 0.069$ & $\$ 0.052$ & $\$ 0.067$ & $\$ 0.089$ & North Dakota & $\$ 0.023$ & $\$ 0.013$ & $\$ 0.019$ & $\$ 0.012$ \\
\hline District of Columbia & $\$ 0.100$ & N/A & $\$ 0.167$ & $\$ 0.000$ & Northern Mariana Islands & N/A & $\$ 0.000$ & N/A & $\$ 0.000$ \\
\hline Florida & $\$ 0.189$ & $\$ 0.141$ & $\$ 0.186$ & $\$ 0.163$ & Ohio & $\$ 0.129$ & $\$ 0.117$ & $\$ 0.130$ & $\$ 0.128$ \\
\hline Georgia & $\$ 0.647$ & $\$ 0.662$ & $\$ 0.678$ & $\$ 0.659$ & Oklahoma & $\$ 0.222$ & $\$ 0.233$ & $\$ 0.245$ & $\$ 0.364$ \\
\hline Guam & $\$ 0.402$ & $\$ 0.000$ & N/A & N/A & Oregon & $\$ 0.140$ & $\$ 0.129$ & $\$ 0.082$ & $\$ 0.069$ \\
\hline Hawaii & $\$ 0.096$ & $\$ 0.155$ & $\$ 0.153$ & $\$ 0.000$ & Pennsylvania & $\$ 0.116$ & $\$ 0.112$ & $\$ 0.109$ & $\$ 0.144$ \\
\hline Idaho & $\$ 0.068$ & $\$ 0.095$ & $\$ 0.064$ & $\$ 0.089$ & Puerto Rico & $\$ 1.170$ & $\$ 0.000$ & $\$ 0.024$ & $\$ 0.000$ \\
\hline Illinois & $\$ 0.151$ & $\$ 0.113$ & $\$ 0.158$ & $\$ 0.231$ & Rhode Island & $\$ 0.068$ & $\$ 0.086$ & $\$ 0.136$ & $\$ 0.119$ \\
\hline Indiana & $\$ 0.129$ & $\$ 0.111$ & $\$ 0.105$ & $\$ 0.128$ & South Carolina & $\$ 0.028$ & $\$ 0.067$ & $\$ 0.048$ & $\$ 0.156$ \\
\hline lowa & $\$ 0.092$ & $\$ 0.169$ & $\$ 0.080$ & $\$ 0.085$ & South Dakota & $\$ 0.014$ & $\$ 0.016$ & $\$ 0.136$ & $\$ 0.023$ \\
\hline Kansas & $\$ 0.131$ & $\$ 0.127$ & $\$ 0.150$ & $\$ 0.157$ & Tennessee & $\$ 0.199$ & $\$ 0.176$ & $\$ 0.189$ & $\$ 0.182$ \\
\hline Kentucky & $\$ 0.207$ & $\$ 0.205$ & $\$ 0.254$ & $\$ 0.158$ & Texas & $\$ 0.270$ & $\$ 0.144$ & $\$ 0.202$ & $\$ 0.176$ \\
\hline Louisiana & $\$ 0.292$ & $\$ 0.327$ & $\$ 0.344$ & $\$ 0.413$ & Utah & $\$ 0.078$ & $\$ 0.013$ & $\$ 0.105$ & $\$ 0.067$ \\
\hline Maine & $\$ 0.067$ & $\$ 0.069$ & $\$ 0.089$ & $\$ 0.106$ & Vermont & $\$ 0.133$ & $\$ 0.159$ & $\$ 0.122$ & $\$ 0.114$ \\
\hline Maryland & $\$ 0.193$ & $\$ 0.133$ & $\$ 0.200$ & $\$ 0.304$ & Virgin Islands & $\$ 0.728$ & N/A & N/A & N/A \\
\hline Massachusetts & $\$ 0.438$ & $\$ 0.652$ & $\$ 1.223$ & $\$ 0.459$ & Virginia & $\$ 0.180$ & $\$ 0.166$ & $\$ 0.158$ & $\$ 0.196$ \\
\hline Michigan & $\$ 0.153$ & $\$ 0.155$ & $\$ 0.128$ & $\$ 0.154$ & Washington & $\$ 0.231$ & $\$ 0.236$ & $\$ 0.183$ & $\$ 0.226$ \\
\hline Minnesota & $\$ 0.042$ & $\$ 0.328$ & $\$ 0.232$ & $\$ 0.275$ & West Virginia & $\$ 0.093$ & $\$ 0.094$ & $\$ 0.077$ & $\$ 0.077$ \\
\hline Mississippi & $\$ 0.340$ & $\$ 0.322$ & $\$ 0.445$ & $\$ 0.498$ & Wisconsin & $\$ 0.258$ & $\$ 0.143$ & $\$ 0.284$ & $\$ 0.327$ \\
\hline Missouri & $\$ 0.103$ & $\$ 0.072$ & $\$ 0.110$ & $\$ 0.223$ & Wyoming & $\$ 0.118$ & $\$ 0.096$ & $\$ 0.087$ & $\$ 0.076$ \\
\hline Montana & $\$ 0.149$ & $\$ 0.154$ & $\$ 0.140$ & $\$ 0.124$ & & & & & \\
\hline
\end{tabular}

Note: Current as of August 2004, when funding decisions for 2004 applications had not yet been made.

discounts. What are the long-term impacts of CIPA's requirements on the number of libraries seeking E-rate funding? How does CIPA affect whether libraries or library consortia apply for E-rate discounts? Does CIPA affect what types of discounts libraries or library consortia apply for? How are affected libraries and library consortia implementing CIPA's requirements?

- Lessons from the temporary moratorium on funding. As the FCC has already temporarily suspended distribution of E-rate awards once, it is not inconceivable that similar moratoria may occur in the future. 
If a moratorium were to interrupt the awarding of discounts for any significant amount of time, it would have the potential to create many short- and long-term economic and technological problems for libraries and library consortia. In such a case, where could libraries turn for alternate sources of funding? Would any libraries have to limit or eliminate services as a result of another moratorium?

- Policy analysis. Since nearly a decade has elapsed since the original passage of the legislation establishing the E-rate, it is time to conduct a formal policy analysis of the law and the resultant policies and regulations. Such an analysis can determine the degree to which changes in the law and regulations might be needed in light of subsequent laws and policies. This type of analysis would be particularly beneficial in cases where libraries have a chance to express their perspectives in the legislative process.

There are likely to be other research topics, but these represent some of the most important areas where further research on E-rate is needed to better understand what the program is doing, how it can be improved, and what can be done to ensure that libraries, library consortia, and library patrons continue to benefit from the E-rate program.

\section{Recommendations}

As the data presented in this article suggest, the E-rate program has provided significant benefits to libraries and library consortia. The discounts provided by E-rate have provided more than $\$ 250$ million to libraries and library consortia for technology and services that allowed the acquisition of Internet and telecommunications access that might not otherwise be available. The patrons and staff at many libraries enjoy the technological benefits of the E-rate program on a daily basis. The program, however, might still be improved to better meet the needs of libraries and library consortia:

- Provide oversight. There is a need for a better system of record keeping, monitoring, and reporting of E-rate program activities. Improvements in these practices would not only help make the program work better for the organizations that it serves, it would better show what the program accomplishes and would serve to instill greater confidence that the program is making valuable and meaningful contributions to society.

- Use alternate measures in determining program eligibility. E-rate applications by libraries are tied to poverty measures related to schools in the community. This method may not necessarily be the most effective or efficient means to ascertain how much assistance a library needs to acquire Internet and telecommunications technology.

- Calculate the E-rate awards libraries receive as part of school and library consortia. Currently, the data do not reveal the amount of awards libraries that are part of a school and library consortia receive. Without such information, the true extent of the role of E-rate in libraries cannot be accurately calculated or studied. Investigating alternate means for measuring E-rate eligibility of libraries may prove beneficial.

- Describe the impact of the E-rate program. There is need to conduct research on the effects of the program. More extensive research on E-rate is needed to better calculate the value of the program to libraries, library consortia, communities, staff, patrons, and other library stakeholders. Research can also provide a better understanding of the issues that libraries consider when deciding whether or not to apply for E-rate discounts.

The E-rate program has resulted in a significant amount of discounts being awarded to libraries over the years of the program. For many libraries, were it not for these awards, the degree to which they could have implemented a range of technologies to support access to and use of the Internet would have been limited. This increased public Internet access has provided many library patrons, particularly in rural and economically disadvantaged areas, with their only meaningful avenue to access the online environment. The E-rate program is extremely important to libraries, library consortia, librarians, and library patrons, and the recommendations in this paper provide a beginning point for a public discussion to shape the future of the E-rate program.

Ultimately, the future of the E-rate program depends on understanding the degree to which it has been successful, being able to provide evidence in support of what it has or has not accomplished, and enhancing the effectiveness with which the library community can engage in the federal policy making process to fine-tune and improve the program. To engage successfully in this political process, additional analysis and research will certainly be necessary.

\section{Acknowledgment}

The authors wish to thank Steven Hodges of the Florida Resources and Environmental Analysis Center at Florida State University for his assistance in extracting information from the raw data supplied by USAC. The authors would also like to thank Bob Bocher, Carrie Lowe, Charlie Parker, and Rick Weingarten for their helpful comments on this paper. 


\section{References and Notes}

1. Telecommunications Act of 1996, Public Law 104-104, 47 U.S.C. sec. 151-614.

2. William E. Kennard and Elizabeth Evans Lyle, "With Freedom Comes Responsibility: Ensuring that the Next Generation of Technologies Is Accessible, Usable, and Affordable," CommLaw Conspectus 10 (2001): 5-22.

3. Library Services and Technology Act, Public Law 104-208, 20 U.S.C. sec. 9121 et seq.

4. Angele A. Gilroy, Telecommunications Discounts for Schools and Libraries: The "E-rate" Program and Controversies (Washington, D.C.: Congressional Research Service, 2004).

5. John Carlo Bertot and Charles R. McClure, "U.S. Public Library Outlet Internet Connectivity: Progress, Issues, and Strategies," Library $\mathcal{E}$ Information Science Research 21, no. 3 (1999): 281-98; John Carlo Bertot, Charles R. McClure, and Joe Ryan, "Impact of External Technology Funding Programs for Public Libraries: A Study of LSTA, E-rate, Gates, and Others," Public Libraries 41, no. 3 (2002): 166-71; John Carlo Bertot et al., Analysis of Public Library E-rate Data: 1999-2002 (Tallahassee, Fla.: Information Use Management and Policy Institute, 2003). Accessed Apr. 5, 2005, www.ii.fsu.edu.

6. Duncan D. Chaplin, "Empowerment Zones and E-rate Application Rates: Is There a Relationship?" Georgetown Public Policy Review 7 (2001): 61-72; Norris Dickard, ed., Great Expectations: Leveraging America's Investment in Educational Technology (New York: Benton Foundation, 2002).

7. Bertot, McClure, and Ryan, "Impact of External Technology Funding Programs for Public Libraries"; Heather E. Hudson, "Universal Access: What Have We Learned from the E-rate?" Telecommunication Policy 28, no. 3/4 (2004): 309-21.

8. John Carlo Bertot and Charles R. McClure, Public Libraries and the Internet 2002: Internet Connectivity and Networked Services (Tallahassee, Fla.: Information Use Management and Policy Institute, 2002). Accessed Apr. 5, 2005, www.ii.fsu.edu

9. Kathy Ishizuka, "Use of E-rate Funds Still Lags: Schools, Libraries Aren't Taking Advantage of Federal Tech Discounts," School Library Journal 50, no. 4 (2004): 22.

10. Bertot et al, Analysis of Public Library E-rate Data.

11. Gilroy, Telecommunications Discounts for Schools and Libraries; John Carlo Bertot, "Universal Service in the Networked Environment: The Education Rate (E-rate) Debate," Journal of Academic Librarianship 26, no. 1 (2000): 45-48; John A. Shuler, "A Critique of Universal Service, E-rate, and the Chimera of Public Interest," Government Information Quarterly 16, no. 4 (1999): 359-69.

12. Gilroy, Telecommunications Discounts for Schools and Libraries; U.S. General Accounting Office, Schools and Libraries Program: Actions Taken to Improve Operational Procedures Prior to Committing Funds (Washington, D.C.: General Accounting Office, 1999); U.S. General Accounting Office, Schools and Libraries Program: Application and Invoice Review Procedures Need Strengthening (Washington, D.C.: General Accounting Office, 2000); U.S. General Accounting Office, Schools and Libraries Program: Update on E-rate Funding (Washington, D.C.: General Accounting Office, 2001).

13. Ken Foskett and Paul Donsky, "Hard Eye on City Schools' Hardware," Atlanta Journal-Constitution, May 25, 2004; Ken Foskett and Jeff Nesmith, "Wired for Waste: Abuses Tarnish E-rate Program; Investigators Target Lapses in Oversight around U.S.," Atlanta Journal-Constitution, May 24, 2004.
14. Children's Internet Protection Act, Public Law 106-554, 20 U.S.C. sec. 9134(f) and 47 U.S.C. sec. 254(h)(6).

15. Paul T. Jaeger, John Carlo Bertot, and Charles R. McClure, "The Effects of the Children's Internet Protection Act (CIPA) in Public Libraries and Its Implications for Research: A Statistical, Policy, and Legal Analysis," Journal of the American Society for Information Science and Technology 55, no. 13 (2004): 1131-39; Paul T. Jaeger and Charles R. McClure, "Potential Legal Challenges to the Application of the Children's Internet Protection Act (CIPA) in Public Libraries: Strategies and Issues," First Monday 9, no. 2 (2004). Accessed Apr. 5, 2005, http://firstmonday.org/issues/ issue9_2/jaeger/index.html; Paul T. Jaeger et al., "CIPA: Decisions, Implementation, and Impacts," Public Libraries 44, no. 2 (Mar./Apr. 2005): 105-09.

16. Norman Oder, "\$40 Million in E-rate Funds Suspended: Delays Caused As FCC Requires New Accounting Standards," Library Journal 129, no. 18 (2004): 16; Debra Lau Whelan, "E-rate Funding Still Up in the Air: Schools, Libraries Left in the Dark about Discounted Funds for Internet Service," School Library Journal 50, no. 11 (2004): 16.

17. Bertot et al., Analysis of Public Library E-rate Data.

18. Gilroy, Telecommunications Discounts for Schools and Libraries.

19. Foskett and Donsky, "Hard Eye on City Schools' Hardware"; Foskett and Nesmith, "Wired for Waste."

20. Bertot and McClure, Public Libraries and the Internet 2002. 